\title{
CONSUMISMO E GOZO: UMA COMPREENSÃO DE IDEOLOGIA ENTRE T.W. ADORNO E J.LACAN' ${ }^{1}$
}

\section{Conrado Ramos}

Resumo: Questiona-se a possibilidade de investigar as relações entre indústria cultural e a dinâmica da satisfação com o consumo no mundo contemporâneo a partir da concepção de indivíduo compreendido como âmbito particular do sujeito da consciência afetado pela dimensão do inconsciente. Propõe-se o redirecionamento para a concepção de sujeito do inconsciente, ao qual pode-se conferir uma universalidade de estrutura e um assujeitamento de seus laços sociais à objetividade histórica. Essa mudança de foco permite pensar o imperativo de gozo como ideologia da sociedade de consumo: a força da ideologia, ao perder a pretensão à autonomia e adaptar-se à realidade material (Horhkeimer e Adorno), desloca-se do "convencimento" e do "auto-engano" que a caracterizava para a dimensão concreta e corporal da compulsividade e da pulsão. Por apoiar-se nas fixações alienantes do sujeito, a ideologia afirma e sustenta a condição neurótica e compulsiva do consumismo e da busca de satisfação particular como norma.

Palavras-chave: Ideologia. Gozo. Consumo.T.W. Adorno. J. Lacan.

Em nossos esforços mais recentes (Ramos, 2006, inédito) de investigação das relações entre indústria cultural/propaganda e a dinâmica da satisfação do indivíduo no mundo contemporâneo, temos nos deparado com a necessidade de direcionar nossas questões para esferas que ultrapassam o âmbito do indivíduo, compreendido como o âmbito particular do sujeito da consciência, ainda

1 Este artigo faz parte de nosso projeto de pesquisa no estágio de pós-doutorado no Núcleo de Pesquisa Psicanálise e Sociedade do Programa de Estudos Pós-Graduados em Psicologia Social da PUC/SP, sob supervisão do Prof. Dr. Raul Albino Pacheco Filho. 
que afetado pela dimensão do inconsciente. Desde que viemos pensando o particular pela mediação do conceito lacaniano de gozo, a noção de indivíduo, tão cara aos autores da Escola de Frankfurt, tem demonstrado suas limitações no que diz respeito ao entendimento daquilo que poderíamos chamar de dominação dos "estratos cada vez mais profundos da estrutura psicológica" (Adorno \& Simpson, 1994, p. 143), ou da investigação dos "poderes objetivos que determinam a existência individual até o mais recôndito nela" (Adorno, 1992, p. 7). Achamos que é o momento, então, de prosseguirmos nossas investigações tendo por pano de fundo não a noção básica de indivíduo, mas a concepção lacaniana de sujeito, isto é, de sujeito do inconsciente, o que pressupõe, antes de mais nada, considerar a seguinte advertência de Lacan (1998a):

Kern unseres Wesen, o âmago de nosso ser: não é tanto a isto que Freud nos ordena visar, como fizeram muitos outros antes dele através do vão adágio do "Conhece-te a ti mesmo": são as vias que a ele conduzem que ele nos dá para revisar. (pp. 530-531)

E vale destacar o que Lacan (1998b) escreve no primeiro parágrafo do primeiro texto de seus Escritos:

Nossa investigação levou-nos ao ponto de reconhecer que o automatismo de repetição (Wiederholungszwang) extrai seu princípio do que havíamos chamado de insistência da cadeia significante. Essa própria noção foi por nós destacada como correlata da ex-sistência (isto é do lugar excêntrico) em que convém situarmos o sujeito do inconsciente, se devemos levar a sério a descoberta de Freud. (p. 13)

Esse redirecionamento nos permitirá trabalhar com conceitos da teoria psicanalítica que nos apontam para o sujeito compreendido como efeito de estrutura e, enquanto ser de fala, excêntrico, marcado pela relação com o Outro e submetido ao processo civilizatório que lhe exige renúncias pulsionais. Essas condições conferem ao sujeito, por um lado, a universalidade de sua estrutura (tal como ela emerge da investigação e da teorização psicanalíticas) e, por outro, o assujeitamento de seus laços sociais à objetividade histórica. Ou, como propõe Freud (1930/1988):

Resta avaliar o último, mas decerto não o menos importante, dos aspectos característicos da civilização: a maneira pela qual os relacionamentos mútuos dos homens, seus relacionamentos sociais, são regulados - relacionamentos estes que afetam uma pessoa como próximo, como fonte de auxílio, como objeto sexual de outra pessoa, como membro de uma família e de um Estado. Aqui, é particularmente difícil manter-se isento de exigências ideais específicas e perceber aquilo que é civilizado em geral. Talvez possamos começar pela explicação de que o elemento de civilização entre em cena com a primeira tentativa de regular esses relacionamentos sociais. (p. 101) 
A distinção formal estabelecida por Freud entre o "elemento de civilização" e os "relacionamentos [laços] sociais" permite-nos supor sua compreensão de universalidade do primeiro e de particularidade do segundo, ou, nos termos de Poli (2004):

O "elemento cultural" funda a humanidade; ele é atemporal posto que mítico [aqui, numa referência da autora à obra de Freud (1913/1988) Totem e tabu].Já os laços sociais estabelecem a história, eles inscrevem ao longo do tempo as formas de enlace que os humanos constituem entre si, o que implica também nas diferentes formas de representar este ato primeiro [ato de fundação da cultura, isto é, o assassinato do pai da horda primeva]. (p.43, colchetes nossos)

O acirramento das tensões que surgem com a articulação de uma teoria estrutural com uma teoria histórica, coloca-nos no atravessamento de um perigoso campo minado. Porém, acreditamos que não é possível seguir adiante na compreensão das relações entre indústria cultural e gozo sem esse risco. Questionar os poderes objetivos a partir de uma teoria que se propõe a alcançar o mais recôndito no sujeito, sem perder de vista a objetividade e a historicidade de tais poderes e o caráter excêntrico desse mais recôndito, esse é o nosso caminho neste projeto de pesquisa.

Escolhemos como objeto o imperativo de gozo, tema já bastante desenvolvido por autores do campo lacaniano, como Slavoj Zizek. O contexto no qual nos inserimos é o da sociedade do consumo, ${ }^{2}$ dentro da qual, se concordarmos com as condições de sua existência, o consumismo emerge com um valor moral. Sobre isso, em outro trabalho dissemos:

a saciedade própria da sociedade de consumo burguesa recobre o vazio material com um espírito vazio e põe no imperativo de gozo consumista a missão de falsificar a superação da contradição entre o acúmulo e a distribuição dos bens. Num shopping center tudo se passa como se ao mesmo tempo estivessem presentes a abundância e a distribuição dos bens e a alegre excitação do acúmulo dos mesmos. Além disso, assim como Kant (1974) pôde ver no imperativo moral formalizado a antecipação da liberdade, também a sociedade de consumo trouxe a ficção da abundância material com a materialização dos produtos culturais e de milhões de informações esvaziadas distribuídas pela internet. Se a lei formal não pode ter conteúdo para que a liberdade seja possível, também a mercadoria não

2 Compreendemos a sociedade do consumo como aquela caracterizada pelo alto volume de produção e aquisição de bens que não atendem às necessidades básicas, mas a necessidades efêmeras que são socialmente produzidas pela propaganda, associado à elevada disponibilidade de crédito (Outhwaite \& Bottomore, 1993; Severiano, 1999) e ao conseqüente desenvolvimento do acúmulo do capital. Sabemos que uma sociedade como esta não seria possível sem o avanço tecnológico alcançado na produção e comunicação. Insistimos, assim, na importância do consumo como vínculo social que define contemporaneamente as relações entre o particular e a totalidade, pela dimensão da demanda manipulada e da produção/distribuição/comunicação administradas. Estas relações não são compreendidas como decorrências naturais ou inevitáveis, mas como historicamente produzidas pelos interesses do capital, estando assim submetidas a esferas objetivas de poder e dominação. 
tem mais substância. $\mathrm{O}$ dever e o consumir antecipam e confundem liberdade e abundância: tão maior é o consumo e o poder de compra, tanto mais livre o indivíduo se sente. Só isso dá sentido à indiferença quanto ao "o que" e ao "para que"se compra:é tal qual um dever moral, cuja formalização o"- Goza!"lacaniano permite perceber. (Ramos, 2004, pp.47-48)

\section{E concluímos:}

Não podemos, de maneira equivalente, dizer que o consumismo seja uma força capaz de trazer autonomia, reflexão ou autodeterminação. Se o conteúdo da moral kantiana é ideológico por falta de concretização histórica, ele é verdadeiro enquanto for uma necessidade histórica e social do indivíduo. Já o consumismo é uma ideologia completa, pois embora já tenha se concretizado historicamente, seu conteúdo não apresenta outra função senão a de manter escondida a má distribuição material - coisa que já não consegue - e o processo de produção e de acúmulo de capital. (Ramos, 2004, p. 48)

Cumpre-nos, a partir de agora, aprofundar as articulações entre o imperativo de gozo e o consumismo com a ideologia, o que faremos recorrendo inicialmente às concepções de ideologia desenvolvidas por Horkheimer e Adorno (1973) e Zizek (1996).

\section{Imperativo de gozo como ideologia da sociedade do consumo}

Segundo Horkheimer e Adorno (1973),"o estudo concreto do conteúdo ideológico da comunicação de massa é tanto mais urgente quando se pensa na inconcebível violência que os seus veículos exercem sobre o espírito dos homens" (p. 202). A questão central que essa citação nos propõe é: de que modo essa ideologia se constitui, se sustenta e se manifesta na dimensão do sujeito? Propomos como hipótese a seguinte resposta: por aquilo que nos esclarece a compreensão do consumismo como resposta a um imperativo de gozo.

Horkheimer e Adorno abordam a questão da ideologia no particular buscando entender como e porque o indivíduo passa a "viver" a ideologia, a representá-la como sendo a única forma de encontrar uma substância, um fundamento para a existência e uma auto-referência identitária. $O$ indivíduo converte-se na ideologia, identifica-se com ela e se torna indivíduo por esse meio: pseudoformação e pseudo-individuação. Desse modo, não se trata de uma compreensão pragmática pautada pela "razão cínica", pela qual o indivíduo "sabe" da ideologia e a vive mesmo assim, assumidamente, como se diante da inverdade que ela implica não houvesse mais o que fazer a não ser gozar, como for possível, de sua falsidade. Trata-se de compreender esse cinismo como a própria ideologia, ou seja, o problema da ra- 
zão cínica não é "saber" que "tudo é ideologia", mas achar que não há outra realidade possível. A razão cínica não é uma saída para a ideologia, apontando para um mundo "pós-ideológico", mas é a expressão mais exemplar da ideologia contemporânea.

A "razão cínica" como concepção da ideologia contemporânea pressupõe que a ideologia perdeu seu componente de falsidade, havendo "consciência" da falsa consciência e uma adesão que, por esse princípio, pode-se entender como "voluntária" e, por isso mesmo, cínica. Na realidade, a ideologia perdeu o princípio de autonomia que, por muito tempo, caracterizou-a: ela não simula mais uma pretensa autonomia do espírito em relação à realidade material. Não havendo mais esse distanciamento, a ideologia adapta-se à realidade material:"esta adaptação realiza-se mediante os produtos da indústria cultural" (Horkheimer \& Adorno, 1973, p. 200). Suas funções atuais são "atrair as massas em sua condição de consumidoras" e "adaptar e fixar o seu estado de consciência" (p. 200). Nesse sentido, "será preferível analisar a que configurações psicológicas querem se referir, para servirem-se delas; que disposições desejam incutir nos homens" (p. 192). Trata-se, antes, de compreender a adesão cínica e conformista não como a prova de um mundo pós-ideológico, mas como o resultado mais concreto da ideologia, tendo em vista aquilo que ela se tornou por sua própria transformação histórica. A força da ideologia, ao perder a pretensão à autonomia e adaptar-se à realidade material, desloca-se do "convencimento" e do "auto-engano" racional/espiritual para a dimensão concreta/corporal da compulsividade, da impulsividade, da pulsão.

O imperativo categórico perde também sua aparência espiritual e autônoma para se transformar num "dever gozar". Numa forma por demais simplista, mas significativa: a ideologia perde a razão e alcança o corpo. Assim sendo, a definição mais elementar de Marx sobre a ideologia - "disso eles não sabem, mas o fazem" (Zizek, 1996, p. 312) -, deve dirigir-se não à consciência (posto que "sabem" da ideologia), mas à dimensão na qual o corpo se inscreve na cultura, qual seja, a da pulsão e do gozo: o "disso" de que "eles não sabem" é que "gozam a ideologia" por meio da sustentação social de suas neuroses e da afirmação objetiva de suas alienações narcísicas. O que leva um consumidor compulsivo a agir, mesmo sabendo de todas as implicações políticas de suas ações, é um dever gozar que lhe atravessa na forma alienada do "amor à Lei",e disso ele não sabe. A questão da adaptação ideológica do particular à totalidade precisa alcançar seu gozo antes de responder se sua consciência é cínica, alienada ou esclarecida. A crítica ideológica decorrente não deve, assim, limitar-se à razão, mas precisa atingir as fixações alienantes do sujeito, suas posições de gozo, lá onde a teoria social não pode alcançá-lo e precisa cada vez mais da psicanálise.

Neste jogo, a indústria cultural consegue apresentar-se como espírito objetivo, na mesma medida em que readquire, em cada vez maior grau, tendências 
antropológicas em seus clientes. Ao apegar-se a essas tendências, ao corroborálas e proporcionar-Ihes uma confirmação, pode simultaneamente eliminar ou até condenar, de forma explícita, tudo o que rejeitar a subordinação. (Horkheimer \& Adorno, 1973, p. 202)

Compreendemos aqui que estas "tendências antropológicas" manifestam-se na forma do dever gozar próprio das fixações alienantes do sujeito do inconsciente.

Por apoiar-se nas fixações alienantes do sujeito, na cristalização de suas posições de gozo, a ideologia afirma e sustenta a condição neurótica e compulsiva do consumismo e da busca irrefreada de satisfação particular como norma, transformando toda posição contrária em recriminável e toda interposição em obstáculo. A racionalidade tecnológica, que transforma todo objeto em meio para um único fim e justifica os meios pela "dignidade moral" do fim (aqui, entenda-se bem, pressupondo-se a moral do "- Goza!"), emerge como a forma de pensar propícia e bem-vinda ao particular adequado à totalidade. É justamente por esse mecanismo de afirmação do existente, ao invés de falseá-lo com construções objetivas e pretensamente autônomas do espírito, que a ideologia da sociedade do consumo se manifesta na realidade social:

Para resumir numa só frase a tendência inata da ideologia da cultura de massa, seria necessário representá-la numa paródia da frase: “Converte-te naquilo que és", como duplicação e super-ratificação da situação já existente, o que destruiria toda a perspectiva de transcendência e de crítica. O espírito socialmente atuante e eficaz limita-se aqui a por, uma vez mais, diante dos olhos dos homens o que já constitui a condição de sua existência, ao mesmo tempo que proclama o existente como sua própria norma; e, assim, confirma-os e consolida-os na crença, carente de verdadeira fé, em sua pura existência. (Horkheimer \& Adorno, 1973, pp. 202-203)

De modo sintético, o deslocamento histórico do seu foco, da consciência para a dimensão pulsional neurótica e seu mecanismo social de repetição e reafirmação do existente e da alienação narcísica, condensam a ideologia na invocação moral do "-Goza!", compreendida também pelo que sustenta de relação imediata (mimese) do particular com o todo e pela falsa reconciliação que assim sugere existir.

Como alertam Horkheimer e Adorno (1973), por alimentar-se da afirmação do existente, a ideologia pode revelar-se em sua falsidade e expressar a dominação que, desse modo, não oculta, posto que sua inverdade vem do axioma de que as coisas "não poderiam ser diferentes do que são" (p. 203). A sustentação desse axioma, de modo cínico, esclarecido, desesperado, alienado ou hedonista, compõe a adaptação conformista necessária à manutenção do status quo. Compreendemos que a ideologia predominante, assim, não é mais aquela que esconde a realidade material da domi- 
nação sob o manto de uma "falsa realidade" correspondente à autonomia do espírito, mas, sim, é aquela que oculta a possibilidade da transformação, seja sob a máscara da necessária ou inevitável adaptação resignada ao existente, seja por meio da afirmação de que a adesão mimética ao todo - a auto-entrega - é infalível meio do gozo.

Se num período anterior à sociedade do consumo, garantida pela aparência da autonomia, a ideologia cristalizava-se em espírito objetivo determinado pela totalidade e com a função de ocultar suas contradições e seus mecanismos de dominação, atualmente a ideologia se despe da "garantia" da aparência de autonomia e revela, sem qualquer vergonha, a contradição e dominação que ocultava, pois, por sua ação na promessa de gozo e na afirmação do existente, o que aparece como objetivamente cristalizado como inverdade é a idéia e o sentimento de "sem saída". Aliada à realidade, o que a ideologia contemporânea oculta não é mais suas contradições, mas a sua historicidade. Naturalizada a realidade, suas contradições perdem a força dialética que possuíam e se reduzem ao âmbito dos conflitos, para os quais basta o tratamento operacional dado aos problemas técnico-administrativos. Em troca da resignação inevitável, inquestionável e absoluta, a ideologia da sociedade do consumo promete satisfação abundante e ininterrupta.Por isso, é à brecha gerada pela falha de sua promessa, ou seja, à insatisfação, que o desmascaramento da sua inverdade, isto é, a possibilidade da transformação da realidade social, deveria ser associada. Afinal, como concluem Horkheimer e Adorno (1973):

Entretanto, precisamente porque a ideologia e a realidade correm uma para a outra; porque a realidade dada, à falta de outra ideologia mais convincente, converte-se em ideologia de si mesma, bastaria ao espírito um pequeno esforço para se livrar do manto dessa aparência onipotente, quase sem sacrifício algum. Mas esse esforço parece ser o mais custoso de todos. (p. 203)

Sobre certa perspectiva, nesse ponto a concepção de Horkheimer e Adorno da crítica à ideologia faz lembrar a de Zizek (1996): na medida em que a ideologia se estrutura e se afirma na e pela própria realidade social existente, a crítica à ideologia supõe a abertura para o "inteiramente outro" da realidade social, isto é, para uma posição própria da negação determinada que se recusa a buscar "dentro" das "regras do jogo" uma reconfiguração adaptativa da realidade, não sendo possível, no entanto, efetivar a crítica com instrumentos de uma "realidade outra", fora do existente, ainda não realizada historicamente:"a verdadeira escolha livre é aquela na qual eu não escolho apenas entre duas ou mais opções no interior de um conjunto prévio de coordenadas, mas escolho mudar o próprio conjunto de coordenadas" (Zizek, 2001, citado por Safatle, 2003, p. 185). A crítica, cujo processo é a negação determinada do existente (e não poderia ser de outro modo, posto que não há uma "meta-realidade"), é pautada no"confronto de entidades espirituais com sua realização, e pressupõe a distinção do 
verdadeiro e do falso no juízo de valores, assim como a pretensão de verdade no objeto da crítica" (Horkheimer \& Adorno, 1973, p. 192). Noutros termos, a crítica só pode ser imanente e centrada no devir de seu objeto, mas sem a antecipação imaginária ou teórica de sua realização futura. O que é "inteiramente outro" já está presente enquanto história não realizada, ao passo que as configurações utópicas do nosso futuro histórico se arriscam a desconectarem-se do objeto e se reduzirem a "projetos" de ajustamento do todo "contaminados" por aquilo do presente do que seria preciso se desprender para superá-lo.

Mas, qual a concepção de ideologia de Zizek?

Para Zizek (1996), enquanto fantasia social que não só constrói uma aparência para a realidade, mas constitui a consistência da própria realidade, a ideologia é um manto que recobre o real (no seu sentido lacaniano). O real surge, assim, como "negatividade" em relação à realidade existente. A crítica aos discursos sociais que objetivam a realidade e sustentam a fantasia social e o apontamento do caráter sintomático (isto é, simbólico) da exceção produzida por esses discursos como forma de assegurar a consistência imaginária da realidade, possibilitam a retirada do véu alienante da ideologia.

Assim, para Zizek como para os frankfurteanos, a ideologia precisa ser pensada na tensão entre particular e totalidade, o que nos leva a fazer deste trabalho um apontamento da falsa reconciliação entre sujeito e sociedade pela ideologia do consumo, mas também a apontar a irredutibilidade do desejo ao que é socialmente imposto, o que constituiria, nas propostas teóricas de Zizek , uma política do Real:“assim, a verdadeira política do Real não é aquela animada pela tentativa violenta de purificação de toda opacidade do social, mas é aquela feita em nome da irredutibilidade dos antagonismos que fundam a experiência do político" (Safatle, 2003, pp. 190-191).

Noutros termos:

Contra uma política das identidades, uma política da universalidade da inadequação.

O primeiro gesto político fundamental consistiria então em sustentar esta liberdade negativa dos sujeitos permitindo que ela se inscreva no campo do reconhecimento político. Isto significaria, por exemplo, sustentar os modos de manifestação da resistência do sujeito aos processos de instrumentalização social do gozo. (Safatle, 2003, p. 184)

Para Zizek e para os frankfurteanos, portanto, a falsidade não é um componente da realidade positiva que precisa ser encontrado e sanado "ortopedicamente", não se trata de uma resolução técnica ou de um ajuste "fisiológico"/funcional da totalidade. A realidade positiva é a própria falsidade que, em sua função ideológica, oculta não algo em si mesma, mas, de si mesma, a própria possibilidade de outras realidades. A contradição que 
assim se oculta com a ideologia não é mais, ou apenas, a das relações de produção, mas aquela que há entre a experiência social da opressão totalitária e a do encontro com o não-idêntico (alteridade não positivada) como expressão do que é historicamente negado.

Essa contradição não pode, no entanto, ser entendida como efeito de uma "fantasia social ideológica", como propõe Zizek (1996), que, ao reduzir a história da totalidade a categorias construídas para a compreensão da particularidade do sujeito, transforma a opressão e a dominação em um "efeito de estrutura","'suavizando-as" pelo efeito ideológico de apagamento da objetividade: a dominação e a opressão, nesse caso, tornam-se "efeitos", também, de um suposto "núcleo duro do real" que persiste no tempo sem ser dialetizado historicamente. A "irredutibilidade do antagonismo", que do ponto de vista da psicanálise corresponde ao inevitável mal-estar, do ponto de vista da teoria social é a contradição que deve ser superada para a transformação social. Se, em alguns momentos, ao menos, a luta de classes responde na concepção de ideologia de Zizek como o "antagonismo" do capitalismo, sua "irredutibilidade" pressupõe que o capitalismo não pode ser superado.

Se a interpretação de ideologia, em Zizek, não pode dialetizar o antagonismo - como tentaram os autores da teoria crítica (em especial Adorno) ao conceber a natureza e o corpo como historicamente negados na dialética do esclarecimento - esse real coletivamente negado por um fantasia social ideológica torna-se o núcleo duro ideológico da própria teoria de Zizek.

Cabe pensarmos se, diante da conseqüência acima para a concepção de ideologia como fantasia social, não serviria, de certo modo, a Zizek, a seguinte crítica de Horkheimer e Adorno (1973):

Ainda hoje a doutrina da cegueira humana inata, um fragmento de teologia secularizada, pertence ao arsenal da crítica vulgar da ideologia; ao atribuir a falsa consciência a um caráter constitutivo dos homens ou ao seu agrupamento em sociedade, de um modo geral, não só se omitem as suas condições concretas mas, de certa maneira, justifica-se essa cegueira como lei natural e o domínio exercido sobre quem a sofre continua baseada em tais leis, como sucederá depois com um discípulo de Bacon, Hobbes. (pp. 185-186)

Do "indivíduo" ao "sujeito": uma proposta metodológica para o aprofundamento da investigação do particular dominado.

Quando sugerimos, dentro de um trabalho que se propõe crítico, o estabelecimento de um discurso composto por componentes estruturais - tais como estão presentes na teoria lacaniana e que, sabemos, muitas vezes parecem irreconciliáveis com propostas frankfurteanas - é porque julgamos que a profundidade da dominação do particular pelo todo não pode mais ser pensada apenas pela via do indivíduo (isto é, de um sujeito da consciência) ou pelos caminhos de uma concepção de eu "senhor de 
si" e consubstanciado, capaz de enfraquecer-se e fortalecer-se e, por meio disso, determinar o maior ou menor controle do particular sobre si mesmo e diante da totalidade. Não se trata de tomar o eu, como conceito freudiano, em uma acepção materialista que, no esforço da crítica, acaba por confundi-lo com o órgão da autoconservação, isto é, reduzindo-o ao agente responsável pela satisfação das necessidades e, por esse meio, atravessado por um viés adaptacionista e naturalizado. Vale lembrar o quanto, mesmo em Freud, o eu aparece como instância constituída por identificações que, por causa disso, revela-se como um lócus de alienação imaginária. Compreendemos que, em diversos momentos, autores da Escola de Frankfurt colocam a acepção materialista da teoria freudiana e o decorrente trabalho da crítica sobre o conceito de pulsão. Aqui, sim, seguimos com eles, marcando o quanto a própria noção de libido revela a fragilidade do eu ao colocá-lo como objeto. Desse modo, preferimos trabalhar com a idéia de sujeito à de indivíduo, não só pelo rigor conceitual que a primeira alcança dentro da psicanálise, mas, também, para evitar a redução que, por vezes, na passagem distraída do sujeito para o indivíduo, embute no conceito de indivíduo o eu como sede da subjetividade.

Se pudermos pensar, na história da teoria psicanalítica, uma distinção interna entre teoria tradicional e teoria crítica - equivalente àquela estabelecida por Max Horkheimer, em 1937 dentro do âmbito da teoria social -, diremos que seu marco central está na subversão do sujeito do pensamento lacaniano que tem, como principal conseqüência teórica, a distinção entre o sujeito do inconsciente e o eu, apresentado a partir de então em sua verdade imaginária e alienante. A partir disso, tanto do ponto de vista clínico quanto teórico, "fortalecer" o eu é afirmar o existente e aprofundar a alienação. Isso não quer dizer que o contrário (enfraquecer o eu) seria o caminho crítico. Trata-se de deslocar o eixo do eu para o sujeito.

Como, então, manter a tensão entre particular e totalidade sem recair em concepções alienantes de eu e de sujeito? Como propor um trabalho de articulação entre a dimensão subjetiva do particular e a totalidade social sem desconsiderar a radicalidade da descoberta freudiana da descentralidade do sujeito da consciência?

As posições de gozo predominantes na cultura nas quais o particular contemporâneo encontra-se fixado não podem ser explicadas sem o esclarecimento de suas mediações objetivas, mas também não podem ser alcançadas, atualmente, sem o instrumental teórico lacaniano de um inconsciente estruturado como linguagem e de um campo de gozo que se expressa no laço social. Desse modo, devido às particularidades do objeto considerado, lá onde as teorias sociais não poderiam chegar à teoria lacaniana, ao propor um laço social no qual se pode vislumbrar o sujeito do inconsciente e suas posições de gozo, demonstra um caminho possível pelo qual podemos avançar se quisermos aprofundar nossas questões e nossos estudos sobre as articulações entre gozo e dominação social (questões essas, de cer- 
to modo, sempre presentes em nosso percurso: vide, por exemplo, Ramos, 1997/2004). Achamos, assim, que apesar da distância epistemológica e metodológica entre a concepção frankfurteana de sociedade e a concepção lacaniana de sujeito, vale o risco de tentar articulá-las sob o princípio de fazer da tensão entre particular e totalidade o meio de emergência da crítica social e dos mecanismos de dominação do sujeito. Se o fazemos, assim, pela via da estrutura, é porque o objeto nos aponta para aquilo que o instrumental lacaniano permite circunscrever por meio da estrutura. Assim, consideramos que os conceitos e as categorias lacanianos ganham um valor objetivo para a teoria social na medida em que se puder revelar sua importância para a análise da adesão do particular à sociedade do consumo.

Se pudermos, com o nosso trabalho, revelar e compreender novos aspectos das relações entre gozo e dominação social, teremos cumprido nossos objetivos em relação ao objeto de investigação que escolhemos. Estamos cientes das discórdias teóricas existentes entre o materialismo histórico e o estruturalismo e sabemos que isso não é um problema secundário, posto que compõe mediação determinante dos resultados desse estudo.

\section{Consumerism and enjoyment: An ideology understanding between T.W. Adorno and J. Lacan}

Abstract: This study questions the possibility of investigating relations between the cultural industry and the dynamics of the satisfaction with consumption in the contemporaneous world, based on the conception of individual taken as the particular reach of the consciousness subject affected by the unconsciousness dimension. The study proposes to redirect to the unconsciousness subject conception, which can be assigned a universality of structure and the subjection of social links to the historical objectivity. This change of focus allows to consider the imperative of enjoyment as the consumption society's ideology: the ideology power, when losing pretension to autonomy and adapting to the material reality (Horhkeimer and Adorno), shifts from characteristic "persuation" and "self-deceiving" to a concrete and corporal dimension of compulsivity and drive. For being supported by alienating fixations of the subject, the ideology states and supports the neurotic and compulsive condition of the consumerism and the search of particular satisfaction as a norm.

Keywords: Ideology. Enjoyment. Consumption. T.W. Adorno. J. Lacan. 


\section{La consommation et la jouissance: une compréhension d'idéologie entre T.W. Adorno et J. Lacan}

Résumé: On questionne la possibilité d'investiguer les relations entre l'industrie culturelle et la dynamique de la satisfaction donnée par la consommation dans le monde contemporain à partir de la conception d'individu compris comme cadre particulier du sujet de la conscience affectée par la dimension de l'inconscient. On propose de se rediriger vers la conception de sujet de l'inconscient, lequel peut conférer une universalité de structure en assujettissant ses liens sociaux à l'objectivité historique. Ce changement d'axe permet de penser à l'impératif de jouissance comme étant une idéologie de la société de consommation: la force de l'idéologie, en perdant la prétention à l'autonomie et en s'adaptant à la réalité matérielle (Horhkeimer et Adorno), passe de "I'acte de convaincre" et de "I'auto-tromperie" qui la caractérisait vers la dimension concrète et corporelle de la compulsivité et de la pulsion. Par le fait de s'appuyer sur les fixations aliénantes du sujet, l'idéologie affirme et maintient la condition névrotique et compulsive de la haute consommation et de la forme de satisfaction particulière comme norme.

Mots-clés: Idéologie. Jouissance. Consommation. T.W. Adorno. J. Lacan.

\section{Consumismo y gozo: una comprensión de ideología entre T. W. Adorno y J. Lacan}

Resumen: Se cuestiona la posibilidad de investigar las relaciones entre la industria cultural y la dinámica de la satisfacción con el consumo en el mundo contemporáneo a partir de la concepción del individuo comprendido como ámbito particular del sujeto de la conciencia afectado por la dimensión del inconsciente. Se propone la redirección para la concepción del sujeto del inconsciente, al cual se le puede medir una universalidad de la estructura y atenerse a sus lazos sociales y su objetividad histórica. Este cambio de foco permite pensar el imperativo del gozo como ideología de la sociedad de consumo: la fuerza de la ideología, al perder la pretensión a la autonomía y adaptarse a la realidad material (Horhkeimer y Adorno), se desplaza del "convencimiento" y del "autoengaño" que la caracterizaba para la dimensión concreta y corporal de la compulsividad y de la pulsión. Por apoyarse en las fijaciones alienantes del sujeto, la ideología afirma y sustenta la condición neurótica y compulsiva del consumismo y de la búsqueda de la satisfacción particular como norma.

Palabras-clave: Ideología. Gozo. Consumo.T.W. Adorno. J. Lacan. 


\section{Referências}

Adorno, T. W. (1992). Minima moralia. São Paulo: Ática.

Adorno, T. W., \& Simpson, G. (1994). Sobre música popular. In G. Cohn (Org.), Theodor W. Adorno (pp. 115-146). São Paulo: Ática.

Freud, S. (1988). Totem e tabu. In S. Freud, Edição standard brasileira das obras psicológicas completas de Sigmund Freud (J. Salomão, trad., Vol. 13, pp. 13-163). Rio de Janeiro: Imago. (Trabalho original publicado em 1913)

Freud, S. (1988). O mal-estar na civilização. In S. Freud, Edição standard brasileira das obras psicológicas completas de Sigmund Freud (J. Salomão, trad., Vol. 21, pp. 67148). Rio de Janeiro: Imago. (Trabalho original publicado em 1930)

Horkheimer, M., \& Adorno, T. W. (1973). Temas básicos de sociologia. São Paulo: Cultrix.

Kant, I. (1974). Fundamentação da metafísica dos costumes. In M. S. C. Berlinck (Org.), Os pensadores (Vol. 25, pp. 195-256). São Paulo: Abril Cultural.

Lacan, J. (1998a). A instância da letra no inconsciente ou a razão desde Freud. In J. Lacan, Escritos (pp. 496-533). Rio de Janeiro: Jorge Zahar.

Lacan, J. (1998b). O seminário sobre "A carta roubada". In J. Lacan, Escritos (pp. 13-66). Rio de Janeiro: Jorge Zahar.

Outhwaite, W., \& Bottomore, T. (Ed.). (1993). Dicionário do pensamento social do século $X X$. Rio de Janeiro: Jorge Zahar.

Poli, M. C. (2004, janeiro/julho). Perversão da cultura, neurose do laço social. Agora, 7(1), 39-54.

Ramos, C. (1997). A autodestruição da crítica e o gozo inconsciente na dialética do esclarecimento: uma articulação entre os pensamentos de Adorno e Lacan. Dissertação de Mestrado, Instituto de Psicologia, Universidade de São Paulo, São Paulo.

Ramos, C. (2004). A dominação do corpo no mundo administrado. São Paulo: Escuta.

Ramos, C. (2006). Indústria cultural, consumismo e dinâmica das satisfações no mundo administrado. In Congresso Internacional A Indústria Cultural Hoje (pp. 1239-1254). Piracicaba, SP: FAPESP, CAPES, DAAD, CNPq e UNIMEP.

Ramos, C. (2008). A administração de modelos identitários para crianças através dos comerciais de televisão. Trabalho Financiado pela Vice-Reitoria de Pós-Graduação e Pesquisa da Universidade Paulista - UNIP: São Paulo. (Trabalho inédito)

Safatle, V. (2003). Posfácio: a política do Real de Slavoj Zizek. In S. Zizek, Bem-vindo ao deserto do Real: cinco ensaios sobre o 11 de setembro e datas relacionadas (pp. 179191). São Paulo: Boitempo Editorial.

Severiano, M. F. V. (1999). As subjetividades contemporâneas sob o signo do consumo Os ideais narcísicos na publicidade da TV: produção e consumo. Tese de Doutorado, Faculdade de Educação, Universidade Estadual de Campinas, Campinas, SP. 
Zizek, S. (1996). Como Marx inventou o sintoma? In S. Zizek (Org.), Um mapa da ideologia (pp. 297-331). Rio de Janeiro: Contraponto.

Conrado Ramos, Núcleo de Pesquisa Psicanálise e Sociedade do Programa de Estudos Pós-Graduados em Psicologia Social da PUC/SP. Endereço para correspondência: Rua Abílio Soares, 932. CEP 04005-003, bairro: Paraíso. São Paulo - SP. Endereço eletrônico: conrado_ramos_br@yahoo.com.br

Recebido em: 28/09/2007

Aceito em: 30/05/2008 